Industrial Health, 1980, 18, 61.

\title{
ADSORPTION CAPACITIES OF ACTIVE CARBON TUBES FOR SAMPLING ATMOSPHERIC VINYL CHLORIDE VAPOR
}

\author{
Yoshimi MATSUMURA \\ National Institute of Industrial Health, 21-1, Nagao, 6-chome, \\ Tama-ku, Kawasaki 213, Japan
}

(Received February 19, 1980)

\begin{abstract}
Adsorption capacities of sampling tubes packed with various kinds of active carbons for collecting vinyl chloride vapor were measured. Among the active carbons with identical particle size, those made from coconut shell and wood were more effective than those from petroleum pitch giving longer breakthrough times. The tubes packed with active carbons of smaller particle sizes adsorbed vinyl chloride vapor for longer periods than those with larger particle sizes. The breakthrough time in adsorbing vinyl chloride flow using active carbon tubes containing $150 \mathrm{mg}$ carbon of a definite type in a glass tube of $4 \mathrm{~mm}$ inside diameter varied depending on the sampling conditions, i.e., the active carbon tube adsorbed the vapor for a longer period when the sampling rate was slower and the humidity in the flow was low.
\end{abstract}

Active carbon tubes are very versatile for dry sampling of atmospheric gas and vapor contamination. The gas sampling properties and the manuals for the use of active carbon tubes of definite types, especially the one specified by NIOSH of the USA, have been investigated and reported ${ }^{1-5}$. However, the gas adsorption capacity of the active carbon tube varies over a wide range depending on the properties of active carbon packed in the tube. It is also affected by the kind of gas sampled and by the sampling conditions. This study concerns the gas adsorption capacities of sampling tubes packed with active carbons which were purchased on the Japanese market and the change of the adsorption capacity of a tube in relation to sampling conditions.

\section{EXPERIMENTAL}

Active carbons used in this experiment consisted of three kinds of coconut shell carbon, two kinds of wood carbon and three kinds of petroleum pitch carbon. The specific surface areas and pore volumes of these active carbons were obtained from nitrogen adsorption isotherms measured on the carbons, which are presented in Table I along with the particle sizes and shapes. 


\section{Y. MATSUMURA}

Table 1. The kinds and the properties of active carbons examined for the sampling of vinyl chloride vapor.

\begin{tabular}{lccccc}
\hline Kind of active carbon & Sign & Shape of particles & $\begin{array}{c}\text { Particle size } \\
(\mu)\end{array}$ & $\begin{array}{c}\text { Specific surface } \\
\text { area }\left(\mathrm{m}^{2} / \mathrm{g}\right)\end{array}$ & $\begin{array}{c}\text { Pore volume } \\
(\mathrm{cc} / \mathrm{g})\end{array}$ \\
\hline Coconut shell & A & Irregular & $590-1320$ & 1205 & 0.1244 \\
& B & & $250-420$ & 1190 & 0.1322 \\
& C & & 250 & 1980 & 0.3770 \\
\hline Wood & D & Irregular & 1020 & - & - \\
& E & & $605-1060$ & - & - \\
\hline \multirow{2}{*}{ Petroleum pitch } & F & Spherical & $205-295$ & 844 & 0.1134 \\
& G & & $250-600$ & 1113 & 0.2072 \\
& H & & $600-800$ & 1169 & 0.1982 \\
\hline
\end{tabular}

The sampling tubes were prepared by packing $50 \mathrm{mg}, 100 \mathrm{mg}$ or $150 \mathrm{mg}$ of each active carbon in a glass tube of $4 \mathrm{~mm}$ inside diameter and sealing with glass wool at both ends. The tubes were evacuated for 2 hours before the examination of the adsorption breakthrough for vinyl chloride vapor.

The adsorption breakthrough of the active carbon tubes was measured by a dynamic adsorption apparatus, a diagram of which is presented in Fig. 1.

In the apparatus, vinyl chloride vapor generated from a permeation tube at a constant temperature of $30^{\circ} \mathrm{C}$ was carried by a nitrogen stream which was obtained from a cylinder at a flow rate precisely controlled with a mass flow controller. Another nitrogen stream was also generated from the cylinder which was saturated with moisture, and was mixed with the above vinyl chloride flow to adjust the final concentration of vinyl chloride at $6.2 \mathrm{ppm}$, the humidity at the desired level in the stream and the flow rate at $100 \mathrm{ml} / \mathrm{min}$ or slower. The flow thus generated and controlled at $25^{\circ} \mathrm{C}$ was introduced into an active carbon tube in a temperature-controlled air chamber. The effluent stream from the tube was drawn into a gas chromatograph fitted with an auto-gas-sampler at

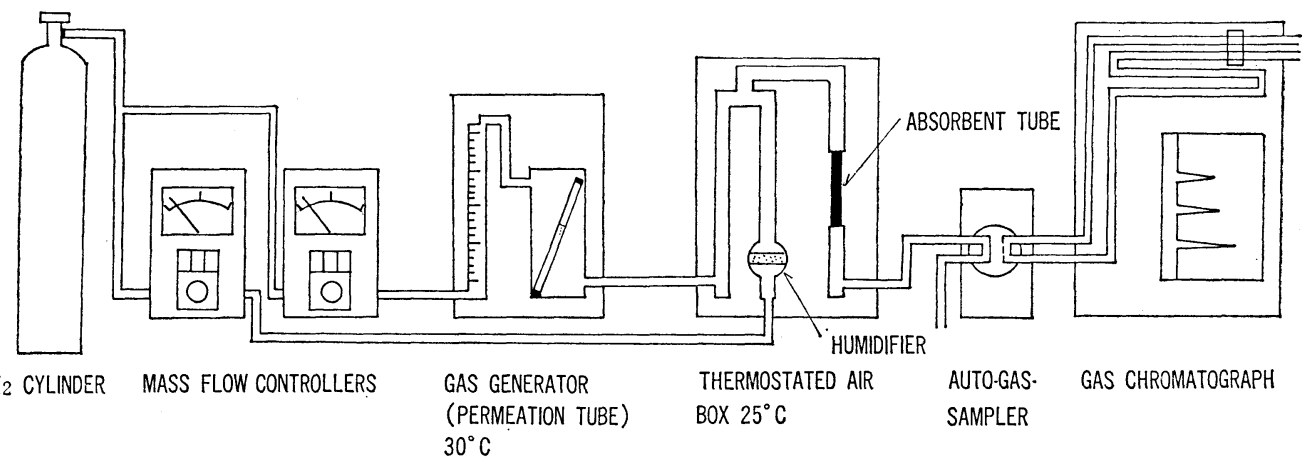

Fig. 1. Dynamic adsorption apparatus for vinyl chloride vapor flow by active carbon tubes. 


\section{SAMPLING VINYL CHLORIDE BY ACTIVE CARBON TUBES}

2 minute intervals and the concentration of vinyl chloride escaping from the tube was observed over this time course. The gas chromatograph used for the analysis was equipped with an FID and a $2 \mathrm{~m}$ column packed with Silicone OV-101. The column temperature was maintained at $60^{\circ} \mathrm{C}$.

\section{RESULTS}

Vinyl chloride in the flow introduced into an active carbon tube was adsorbed for an initial period, after which the vapor began to escape from the tube into the effluent stream. The escaping vapor concentration increased over time as shown in Fig. 2. The breakthrough time of the active carbon tube was determined from the breakthrough curve, as the time when the escaping vapor concentration from the tube reached $1 \%$ of the influent vapor concentration.

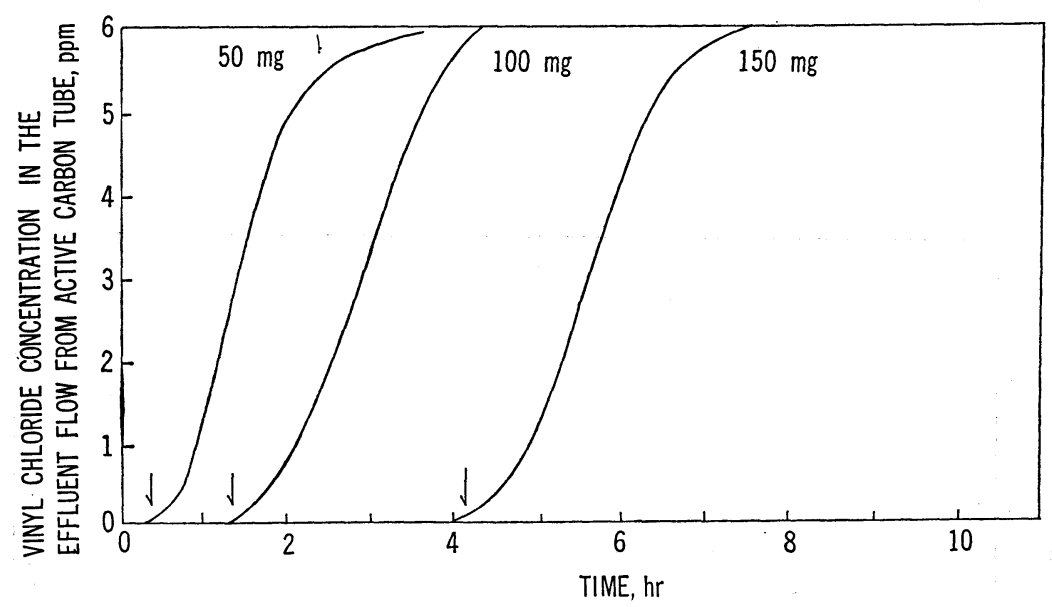

Fig. 2. Breakthrough curves of vinyl chloride in a flow using sampling tubes packed with $50 \mathrm{mg}, 100 \mathrm{mg}$ and $150 \mathrm{mg}$ of active carbon A. Vinyl chloride flow was regulated at a concentration of $6.2 \mathrm{ppm}$, with a flow rate of 100 $\mathrm{ml} / \mathrm{min}$ under anhydrous conditions.

The results in Fig. 3 show that the tubes packed with larger amounts of adsorbent serve for longer periods of sampling.

The measurement of the breakthrough times of active carbon tubes packed with different kinds of active carbons at $6.2 \mathrm{ppm}$ concentration of vinyl chloride revealed the properties of adsorbents suited for sampling tubes. The breakthrough times of sampling tubes packed with active carbons, each at $150 \mathrm{mg}$, are shown in Fig. 4 in relation with the particle size of the carbons. Active carbons with smaller particle sizes proved to adsorb vinyl chloride vapor for longer periods preceding the breakthrough. Among the carbons, those made from coconut shell and wood seemed better suited than those from petroleum pitch, grain size being equal, to get long-life sampling tubes. Active carbon $\mathrm{C}$ showed 


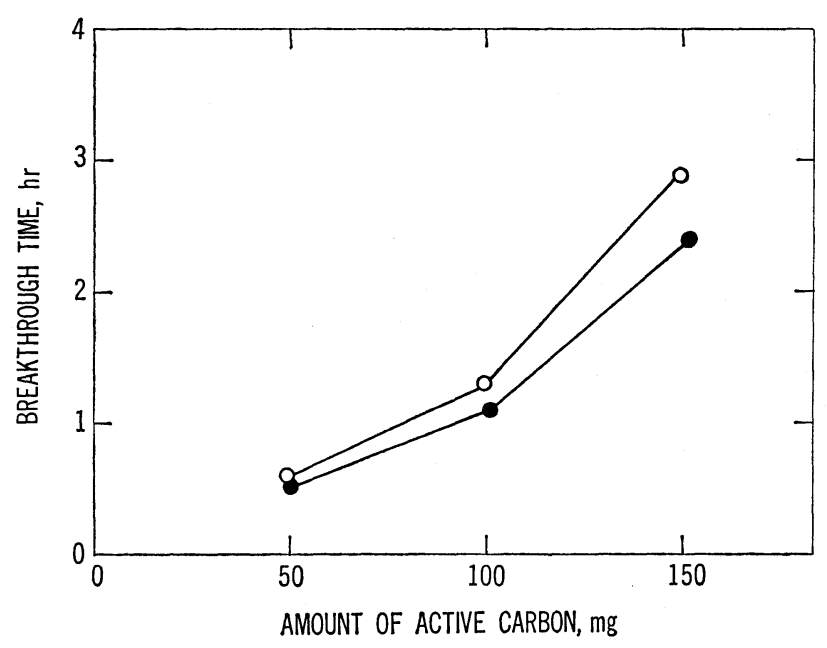

Fig. 3. Breakthrough times of sampling tubes packed with various amounts of active carbon $A(O)$ and $F(O)$. Vinyl chloride flow was regulated at a concentration of $6.2 \mathrm{ppm}$, with a flow rate of $100 \mathrm{ml} / \mathrm{min}$ under anhydrous conditions.

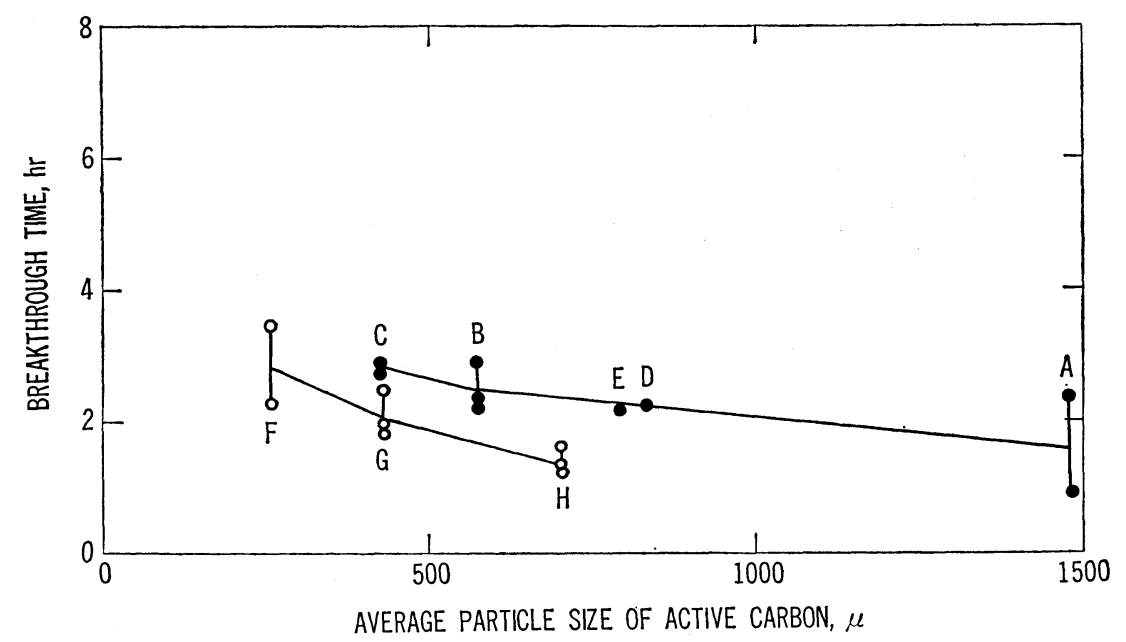

Fig. 4. Breakthrough times for vinyl chloride flow using sampling tubes packed with $150 \mathrm{mg}$ of various kinds of active carbon. Vinyl chloride flow was regulated at a concentration of $6.2 \mathrm{ppm}$, with a flow rate of $100 \mathrm{ml} / \mathrm{min}$ under anhydrous conditions.

breakthrough time not significantly longer than that expected for the breakthrough times of other active carbons considering the relationship between particle size and the breakthrough time, though it has a specially large surface area and pore volume.

When a sampling tube packed with $150 \mathrm{mg}$ of active carbon $\mathrm{A}$ was used to adsorb vinyl chloride in the flow, the breakthrough time varied depending on the flow rate and 


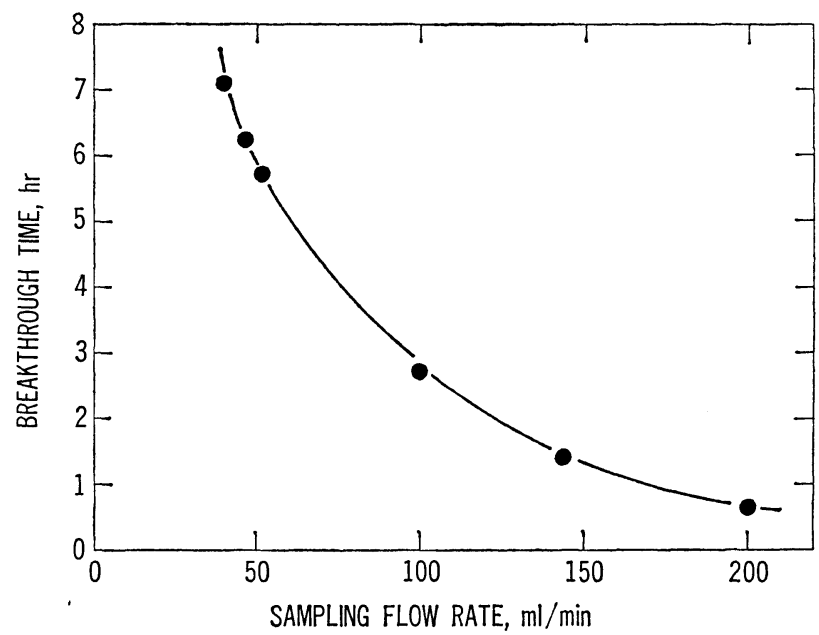

Fig. 5. Breakthrough times for vinyl chloride flow using sampling tubes packed with $150 \mathrm{mg}$ of active carbon A against different flow rates. Vinyl chloride flow was regulated at a concentration of $6.2 \mathrm{ppm}$ under anhydrous conditions.

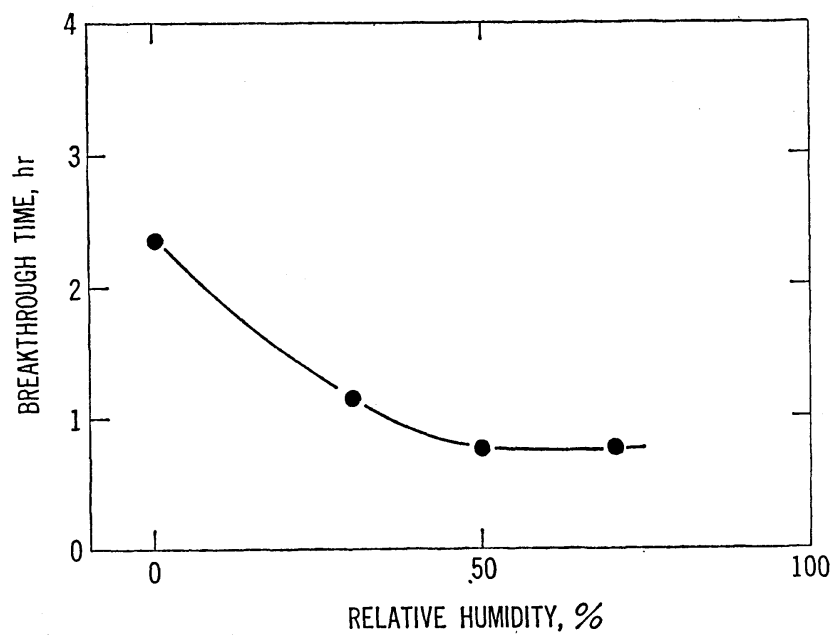

Fig. 6. Breakthrough times for vinyl chloride flow using sampling tubes packed with $150 \mathrm{mg}$ of active carbon A against different humidity. Vinyl chloride flow was regulated at a concentration of $6.2 \mathrm{ppm}$, with a flow rate of $100 \mathrm{ml} / \mathrm{min}$.

on the humidity in the flow. Vinyl chloride concentration was maintained at $6.2 \mathrm{ppm}$. The results given in Fig. 5 show that a sampling tube can serve for continuous sampling for a longer period if the air sampling rate is reduced. The prolongation of the breakthrough time of active carbon tubes due to the reduction of sampling flow rate was more than reciprocally proportional to the flow rate. The shortening of the breakthrough time 


\section{Y. MATSUMURA}

for vinyl chloride sampling due to the moisture in the flow is presented in Fig. 6. At $70 \%$ relative humidity, the sampling tube could adsorb vinyl chloride in about one third the time as that at $0 \%$.

\section{Discussion}

In practical sampling of contaminating organic vapors in the atmospheric air with active carbon tubes, the sampling period must be set shorter than the breakthrough time of the tube under the conditions employed. The experiments performed in this study show that the active carbon tube can serve effectively for sampling organic vapor for a period within the breakthrough time. The breakthrough time varies depending on the sampling rate and the humidity in the air. The shortening of the breakthrough time of the active carbon tube due to the atmospheric moisture content must be noticed, especially in sampling performed on wet days.

The experiments also showed that the choice of the kind of active carbon is important to get sampling tubes with large adsorbing capacities. The active carbons made from coconut shell and wood adsorb vinyl chloride vapor for longer periods than those from petroleum pitch of the same grain sizes though most of them have similar specific surface areas. This could be due to the micropore structure of the carbons determining

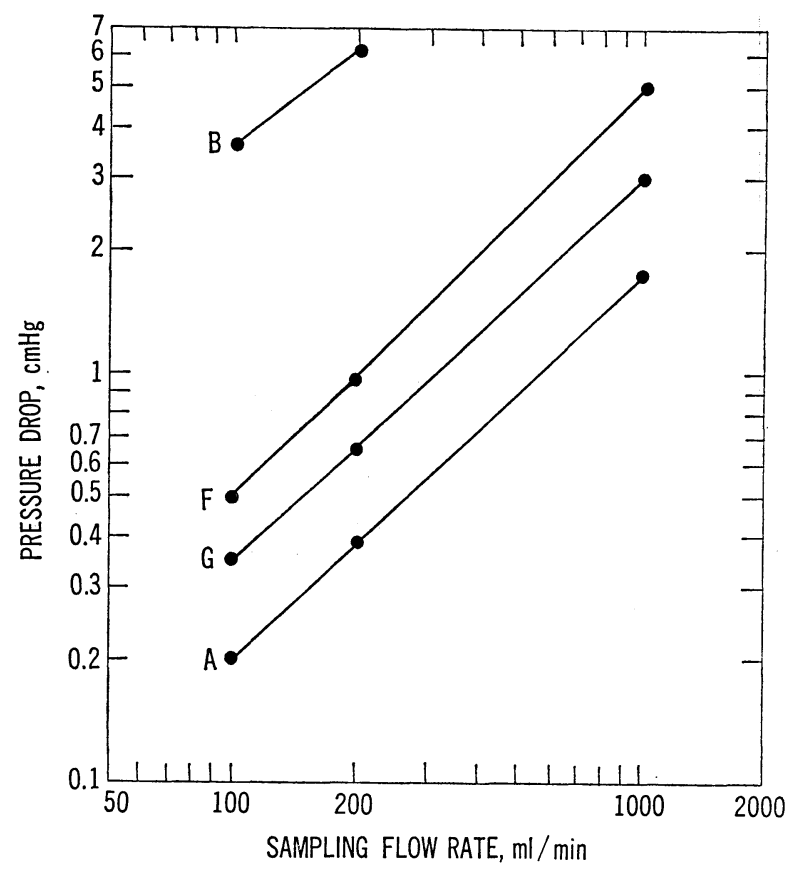

Fig. 7. Pressure drop of air flow due to passing through active carbon tubes in relation with the flow rate. The tubes were packed with active carbons $\mathrm{A}, \mathrm{B}, \mathrm{F}$ and $\mathrm{G}$ of $150 \mathrm{mg}$. 


\section{SAMPLING VINYL CHLORIDE BY ACTIVE CARBON TUBES}

the fraction of the surface available for dynamic gas adsorption, in contrast to the static adsorption of gases at equilbrium, in which the entire surface area, including the outer and inner surface of the micropore structure, is available. Active carbon $\mathrm{C}$, which has a large specific surface area and pore volume, could not serve for long period corresponding to the surface area in the dynamic adsorption of the vapor flow. This would be the result of the too small pore structure; that is, the vapor molecules could diffuse only slowly through small pores.

Active carbon with small particle size is suitable for getting sampling tubes of long breakthrough time, but on the other hand, the tube packed with small particles exhibits high resistance against air flow in suctioning air through it, which would produce a large load to an air suctioning pump. Fig. 7 shows the pressure drops in the air flow caused by active carbon tubes packed with irregular shaped coconut shell carbons and spherical pitch carbons of $150 \mathrm{mg}$ in relation with the air flow rate. Spherical carbons showed advantage over the irregular shaped ones to keep the pressure drop small. Suitable particle size of adsorbents could be determined by taking these two factors into considerations.

The evacuation of active carbon tubes before the gas adsorption is necessary, not only for the removal of pre-adsorbed gases which might otherwise interfere with the gas analysis, but also for the enhancement of the adsorption capacity of the tube. Moisture in the tube has been shown to change the adsorption capacity intensively. These experimental results suggest that the inclusion of a desiccant in the active carbon tube might serve to prolong the breakthrough time of gaseous samples. Another study on a dry method for gas sampling, the author reported that potassium carbonate particles worked effectively for dehydration in air stream without adsorbing the vapors of chlorinated hydrocarbons such as vinyl chloride, vinylidene chloride and carbon tetrachloride. ${ }^{6}$ )

\section{REFERENCES}

1) Taylor, D.G. (1977). NIOSH Manual of Analytical Methods, 2nd ed., NIOSH Publication No. 77-157 A, B and C, NIOSH, Ohio.

2) Miller, B., Kane, P.O., Robinson, D.B. and Whittingham, P.J. (1978). Analyst, 103, 1165.

3) Ahlstrom, D.H., Kilgour, R.J. and Liebman, S.A. (1975). Anal. Chem., 47, 1411.

4) Levadie, B. and MacAskill, S.M. (1976). Anal. Chem., 48, 76.

5) Reid, F.H. and Halpin, W.R. (1968). Amer. Ind. Hyg. Assoc. J., 29, 390.

6) Matsumura, Y. (1980). Jap. J. Ind. Health, 22, 208. 